University of Montana

ScholarWorks at University of Montana

Spring 2013

\title{
The Role of Culture in Advocating for Accurate Diagnosis and Rating of Veterans' Psychological Disabilities
}

Hillary A. Wandler

Alexander Blewett III School of Law at the University of Montana, hillary.wandler@umontana.edu

Follow this and additional works at: https://scholarworks.umt.edu/faculty_lawreviews

\section{Let us know how access to this document benefits you.}

\section{Recommended Citation}

Wandler, Hillary A., "The Role of Culture in Advocating for Accurate Diagnosis and Rating of Veterans' Psychological Disabilities" (2013). Faculty Law Review Articles. 99.

https://scholarworks.umt.edu/faculty_lawreviews/99

This Article is brought to you for free and open access by the Faculty Publications at ScholarWorks at University of Montana. It has been accepted for inclusion in Faculty Law Review Articles by an authorized administrator of ScholarWorks at University of Montana. For more information, please contact scholarworks@mso.umt.edu. 


\title{
The Role of Culture in Advocating for Accurate Diagnosis and Rating of Veterans' Psychological Disabilities
}

\author{
HILLARY A. WANDLER ${ }^{*}$
}

INTRODUCTION .2

I. OVERVIEW OF PSYCHOLOGICAL DISABILITY CLAIMS IN THE VA

DISABILITY SYSTEM .8

A. Disability Compensation Generally .................................. 8

B. The Compensation \& Pension Examination......................... 11

C. Rating a Veteran's Psychological Disability ...................... 13

II. Culture AND Mental Health ..............................................15

A. The Intersection of Culture and Mental Health Generally.15

B. The DSM-IV Cultural Formulation Outline .........................21

C. Culture and Mental Health at the VA...............................26

III. AdVOCATING FOR CULTURALly-INFORMED ASSESSMENT, TREATMENT, AND COMPENSATION IN THE VA SYSTEM.............32

A. Improve Personal Cultural Awareness ..............................32

B. Conduct a Culturally-Sensitive Initial Client Interview......33

C. Gather Culturally-Relevant Supportive Evidence................36

* Assistant Professor of Law, The University of Montana School of Law. I am deeply grateful to my research assistant, Tyler J. Hoyt, who worked tirelessly to find many of the resources in this article and discuss with me what must have seemed like endless variations on this theme; my most recent research assistant, Samir Aarab, has gone above and beyond to answer my last-minute questions. Thank you, as well, to The University of Montana School of Law for funding this research through a summer stipend, to colleagues at the Rocky Mountain Junior Scholar's Forum for critiquing an early rough draft of this article, and colleagues at the LWI's Writers Workshop for critiquing my more recent draft. Carol Wild Scott, Esq., Deputy Director, Case Placement, Case Evaluation \& Placement Component with The Veterans Consortium Pro Bono Program, also generously reviewed and commented on drafts. 
D. Advocate for Culturally-Informed Diagnosis within the VA38

E. Advocate for Culturally-Appropriate Treatment in the VA.39

CONCLUSION AND FUTURE CONSIDERATIONS.................................40

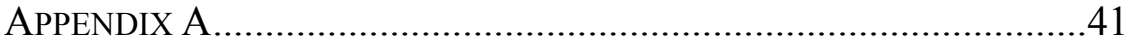

\section{INTRODUCTION}

The Department of Veterans Affairs Compensation and Pension system is complicated. ${ }^{1}$ The disability claims process cannot possibly be boiled down, but one mental image helps illustrate the basic structure of VA compensation. ${ }^{2}$ Picture the Veterans Benefits Administration (VBA) as a large room with a long, straight line painted on the floor. The line has different

1. The Veterans Benefits Manual is a thorough and helpful volume updated each year and widely considered the veterans advocate's "Bible". Veterans Benefits Manual (Barton F. Stichman \& Ronald B. Abrams, eds., 2011). The 2011 Edition is 2,044 pages long. Still, the editors state that "the statutes, regulations, unpublished guidelines, and court decisions governing entitlement to, and the administration of, the VA's monthly income benefits programs are so complicated that a greater endeavor would be necessary to capture all the nuances an advocate could possibly face in representing veterans and their dependents." See Veterans Benefits Manual, supra, at 13; see also Veterans for Common Sense v. Shinseki, 644 F.3d 845, 856 \& note 10 (9th Cir. 2011) (calling the process of applying for disability benefits from the VA "labyrinthine" and noting that claims for mental disorders like post-traumatic stress disorder are among the most complicated for both veterans to complete and VA employees to adjudicate), rev'd en banc on other grounds, 678 F.3d 1013 (9th Cir. 2012).

2. This article explains the disability benefits system in more detail in Section I(A). It would be nice if the process were as simple as described here, but in a system that makes almost 5 million benefits determinations every year with cash payments of over \$25 billion, see VETERANS BENEFITS MANUAL, supra note 1, at 13, true simplicity is an impossible goal. Every part of the disability claims process has several more shades of grey than this article can concisely cover. Nevertheless, the Department of Veterans Affairs could simplify more, including its jargon-heavy publically-distributed forms and statutes; in 2012, it was the only federal agency to receive an "F" grade for compliance with the Plain Writing Act of 2010, legislation that requires federal agencies to write all new publically-distributed documents using principles of plain language. See Plain Language Report Card, CENTER FOR PLAIN LANGUAGE, http://centerforplainlanguage.org/resources/plain-writing-laws/plainlanguage-report-card/ (last visited June 14, 2013) and the press release regarding the agency report cards at Who makes the grade? Plain Language Report Cards for Federal Agencies, CENTER FOR PlaIN LANGuAGe, http://centerforplainlanguage.org/blog/government/who-makes-the-grade/ (last visited June 14, 2013). 
percentage markers, going up by tens, from $0 \%$ to $100 \%{ }^{3}$ Each percentage marker has a counter staffed with a VBA employee who hands out envelopes containing the same amount of money. ${ }^{4}$ For the $100 \%$ marker, the envelopes contain $\$ 2,816,{ }^{5}$ and for each percentage marker below $100 \%$, the envelopes contain a certain measure less; all counters are drawing from a finite pile of money. ${ }^{6}$ A veteran can pick up an envelope once a month from the counter that represents the veteran's percentage of disability; if the veteran is $100 \%$ disabled, the $100 \%$ counter will give the veteran an envelope containing $\$ 2,816$. If instead the veteran is $70 \%$ disabled, the envelope will contain almost $\$ 1,500$ less for the month. ${ }^{7}$ The money in the envelope is intended to compensate the average person (not necessarily the individual veteran) for the amount of money he or she cannot earn through civilian work because of disability. ${ }^{8}$

Before the veteran can get into one of the lines, he or she must go through a gate. The gatekeeper, a VBA employee known as a "rating specialist," must first decide whether the veteran

3. See Veterans Benefits Manual, supra note 1, at 13 ("Unlike disability determinations for social security benefits, for which a total disability is required, disability ratings for VA benefits are made in increments of 10 percent. The higher the degree of disability, the higher is the monthly disability payment.").

4. VETERANS BENEFITS MANUAL, supra note 1, at 59 ("The dollar amount of disability compensation payment at each disability level is exactly the same for everyone, whether he or she is a neurosurgeon or sanitation worker.").

5. See Veterans Compensation Benefits Rates Tables - Effective 12/1/12, U.S. DEP'T VETERANS AFF., http://benefits.va.gov/COMPENSATION/resources_ comp01.asp (last visited June 14, 2013).

6. The Veterans Benefits Administration (VBA) requested $\$ 59.8$ billion to pay for the disability Compensation program in 2013. This amount is requested to pay out compensation benefits to 3,626,468 veterans, 356,796 survivors of veterans, and 1,151 children of veterans in 2013. Annual Budget Submission (FY 2013): Volume III, Benefits and Burial Programs and Departmental Administration, U.S. DEP'T VETERANS AFF., http://www.va.gov/budget/docs/summary/Fy2013_Volume_ III-Benefits_Burial_Dept_Admin.pdf(last visited June 14, 2013).

7. Veterans Compensation Benefits Rates Tables, supra note 5 (Table labeled "70\% - 100\% Without Children").

8. See 38 C.F.R. $§ 4.1$ (2011) (describing the "evaluative rating" in general). Section 4.1 states that a rating is designed to "represent as far as can practically be determined the average impairment in earning capacity" caused by a disease or injury and its residual effects. 
should be allowed through the gate, ${ }^{9}$ and then decide which line the veteran belongs in. To decide which line the veteran belongs in, the gatekeeper will usually require the veteran to be examined by a doctor, who will report on the veteran's medical or psychiatric condition(s) and how well the veteran is functioning. ${ }^{10}$ The gatekeeper will rely heavily on the medical report to place the veteran in a particular line. ${ }^{11}$

An advocate's goal is to help the veteran get through the gate and into the right line, or that line leading to the envelope that most appropriately compensates the veteran for how much the disability actually impairs his or her ability to earn income. This advocacy process is not easy.

Rather than navigating a simple straight line, advocating for a veteran while the VA is determining the percentage assigned to a veteran's disability feels more like navigating a maze with ever-changing routes. If an advocate helps a veteran develop a

9. A VBA employee will first determine whether the person applying for disability compensation is eligible to receive VA benefits. This includes determining whether the person satisfies the statutory definition of "veteran." See VETERANS BENEFITS MANUAL, supra note 1, at 23 ("The first question to ask when determining whether a person is eligible to receive benefits from the VA is - is this person a veteran?”); 38 U.S.C. $§ 101(2)$ (2006) (“The term 'veteran' means a person who served in the active military, naval, or air service, and who was discharged or released therefrom under conditions other than dishonorable."). The second hurdle for a veteran to clear before getting "through the gate" is to show that something happened in service to injure the veteran or cause the veteran to acquire a disease, and the veteran's current disability can be linked to that in-service incident. See VETERANS BENEFITS MANUAL, supra note 1, at 62-63.

10. Although a veteran can (and often should) submit a private physician's opinion in support of a disability claim, particularly for a psychological disability claim, the VA has a duty to assist the veteran in obtaining competent medical evidence in support of the claim. 38 U.S.C. $\$ 5103 A(a)$ (2006) ("The Secretary [of the VA] shall make reasonable efforts to assist a claimant in obtaining evidence necessary to substantiate the claimant's claim for a benefit under a law administered by the Secretary.”). Even if the veteran submits a private physician's diagnosis, the veteran will typically be required to submit to an examination by a Veterans Health Administration physician. See Veterans Benefits MAnual, supra note 1, at 72-73.

11. See Veterans Benefits MANUAL, supra note 1, at 283-85 ("When evaluating a disability the rating activity examines the veteran's medical records to ascertain the medical diagnosis for the particular service-connected disability at issue. The rating activity then finds the appropriate diagnostic code for the disability and selects the degree of disability that corresponds with the symptomatology of the veteran's condition."). 
claim from the beginning, the advocate and veteran can expect to encounter multiple medical and psychiatric exams, unpredictable communication with ratings specialists (if they are fortunate enough to be able to talk with them-they are not, in reality, readily accessible "at the gate"), piles of paperwork, and complicated calculations when factoring in multiple disabilities (something most veterans must do).

If an advocate is helping a veteran develop a claim for a psychological disability, the challenges quickly compound. ${ }^{12} \mathrm{~A}$ physical disability lends itself to diagnosis through lab results and objective observation of symptoms; a doctor can quickly see if the veteran is missing a limb or has a broken bone, for instance. The doctor will listen to the veteran describe symptoms, but will usually rely more heavily on the objective measures rather than the veteran's descriptions. But if the veteran suffers from a psychological disability, the diagnosis must be, at least in part, based on the veteran's own description of symptoms or subjective complaints. "Unlike AIDS or cancer, mental illnesses cannot be diagnosed with a brain scan or blood test. The impressions of doctors-drawn from verbal and nonverbal cues-determine whether a patient is healthy or sick." 13 Add to this the unique context of the VA system in that the psychiatrist examining the veteran is diagnosing for an administrative, rather than therapeutic, purpose, at the request of the VBA gatekeeper. The psychiatrist's role is less a helper and more a pseudo-gatekeeper, and he is certainly more skeptical or adversarial with a veteran seeking part of a finite pool of money than he might be with a client he planned to treat long term. ${ }^{14}$

12. “[D]isability claims for mental disorders present many unique challenges for claimants and their advocates." VETERANS BENEFITS MANUAL, supra note 1, at 152.

13. Shankar Vedantam, Racial Disparities Found in Pinpointing Mental Illness, WASH. POST, June 28, 2005, http://www.washingtonpost.com/wpdyn/content/article/2005/06/27/AR2005062701496.html (last visited June 14, 2013).

14. See Harvey D. Lomas \& Jonathan D. Berman, Diagnosing for Administrative Purposes: Some Ethical Problems, 17(4) Soc. ScI. MED. 241, 241-42 (1983) (exploring the differences between a physician's diagnosis for therapeutic reasons and a physician's diagnosis for purposes of disbursing public funds). 
All of this combines to make communication between the veteran and the medical examiner a truly pivotal part of the veteran's claim.

This is where veterans' cultural backgrounds and identities can become crucial factors in their journeys through the claims process, with the potential to significantly impact which lines they get placed in. Any person's cultural identity is intimately intertwined with his or her psychology. Culture adds a layer of complexity to diagnosing a client suffering from a mental illness. That combines with yet another layer of complexity when a psychiatrist examines a veteran who has served in combat and endured one of humanity's most extreme experiences, and whose personal cultural identity has inevitably intermixed with military culture.

Imagine, for example, your veteran client, John Smith, has been examined by a psychiatrist and you are reviewing the report. John served in Vietnam and he has suffered from symptoms that you believe fit the diagnostic criteria for Post-Traumatic Stress Disorder (PTSD). John told you he has a hard time interacting with co-workers who remind him of people he encountered in combat in Vietnam, but you don't see any mention of this in the psychiatric report. 'It doesn't look like you talked with him about your anger problems with some of your co-workers, especially those who reminded you of people you were in combat against," you say. "Why didn't you tell him about that? Remember, it is important for diagnosing PTSD," you remind him. He responds, "The psychiatrist was Asian, and ever since Vietnam, I can't bring myself to be comfortable in that situation. No way I could talk about that with him."15 In this scenario, an important aspect of the

15. This example is loosely based on situations the author has seen in practice representing disabled veterans seeking disability compensation for psychological disabilities. It is an example of dominant culture mixing with military culture in a way that made it difficult, if not impossible, for the veteran to describe certain symptoms to a C\&P examiner in a short and isolated (not for treatment) encounter. A review of Board of Veterans' Appeals decisions reveals that avoidance of things related to Asian culture, including people of Asian descent, is not a unique manifestation of PTSD symptoms for Vietnam-era Veterans. See, e.g., BVA Docket No. 08-23, 135A (2011), available at BD. OF VETERANS' APPEALS, http://www.index.va.gov/search/va/bva.html (search by case number 1135792) (decision granting a total disability rating in part due to the Veteran's difficulties at work related to his PTSD symptoms that manifested as disagreements with 
veteran's condition is getting lost in translation due to cultural factors. That can potentially derail an accurate picture of the severity of the condition and negatively impact the VA's disability rating.

Culture seems to be "enough of an abstraction that people can be part of the same culture, yet make different decisions in the particular." ${ }^{, 16}$ So, what concrete steps can a lawyer, untrained in multicultural psychiatric diagnosis, take to make sure a veteran's condition does not get lost in translation? The first and most important step is to learn about the veteran's cultural background and identity and how it might impact the way the veteran communicates with the gatekeepers in the system, most importantly medical examiners. Awareness will make lawyers more effective at all stages of the disability claim and appeal process; it will enable them to identify ways they can make veterans' cultural backgrounds and identities a part of the record and a part of the diagnostic and rating procedures. Lawyers who appreciate cultural background and identity in their veteran clients and themselves will be agents of positive change in the VA disability system, moving it toward more culturally-sensitive and appropriate assessment, treatment, and compensation of all veterans.

We have steadily advanced in our understanding of culturally competent approaches to lawyering. ${ }^{17}$ This article builds on our understanding by focusing on the specific context of veterans who have psychological disability claims in the VA disability system. This is a context in which culturally aware communication can be of critical importance to the outcome of a veteran's claim and future livelihood. This article does not presume to advise mental health professionals on cross-cultural

coworkers who reminded him of "Orientals" in Vietnam); See also, BVA Docket No. 08-14, 405 (2010), available at BD. OF VeterAns' APPEALS, http://www.index.va.gov/search/va/bva.html (search by case number 1020316) (Veteran diagnosed with PTSD reported limiting her lifestyle to avoid things and people that reminded her of Vietnam, including people, activities, and places that reminded her of Asian culture).

16. Susan Bryant, The Five Habits: Building Cross-Cultural Competence in Lawyers, 8 CLINICAL L. REV. 33, 41 (2001-2002).

17. See, e.g., Carolyn Copps Hartley \& Carrie J. Petrucci, Practicing Culturally Competent Therapeutic Jurisprudence: A Collaboration Between Social Work and Law, 14 WASH. U. J.L. \& POL'Y 133 (2004). 
counseling practices. Much has already been written on that subject, including in the legal context. ${ }^{18}$ It also does not attempt to answer the empirical question of how culturally un-informed assessment impacts diagnosis, for instance whether it results in over-diagnosis, under-diagnosis, or misdiagnosis of psycholorgical disabilities. Instead, this article proposes that the intersection of culture and mental health is a uniquely important topic of conversation and development for lawyers representing veterans with psychological disability claims. The first section provides a brief overview of psychological disability claims in the Department of Veterans Affairs Compensation and Pension system. The second explores how culture interacts with mental health and the implications of this interaction on psychological diagnosis and treatment. After reviewing some important illustrations of culture's impact on diagnosis in the VA, the article identifies points in the VA disability claims process where veterans' advocates who are aware of and educated in their clients' cultural backgrounds and identities may advocate for culturallysensitive psychological diagnosis, disability rating, and treatment.

\section{OVERVIEW OF PSYCHOLOGICAL DisABILITY ClAims IN THE VA DisABILITY SYSTEM}

\section{A. Disability Compensation Generally ${ }^{19}$}

Individuals who meet the definition of "veteran" may apply for benefits from the U.S. Department of Veterans Affairs, known

18. See, e.g., Tam B. Tran, Using DSM-IV to Diagnose Mental Illnesses in Asian Americans, 10 J. CONTEMP. Legal Issues 335 (1999) (arguing that mental health professionals should begin to use the then recently-developed DSM-IV Cultural Formulation Outline to more accurately assess and diagnose mental health issues in Asian American patients).

19. This article does not fully educate readers in the VA disability compensation system, but instead highlights a crucial consideration in advocating for veterans within that system; thus, this is a simplification of the many nuances of the VA disability compensation program. For a thorough explanation of VA disability compensation and effective advocacy for veterans filing compensation claims, the author highly recommends the Veterans Benefits Manual published by Lexis Nexis and written by staff at the National Veterans Legal Services Program. VETERANS BENEFITS MANUAL, supra note 1. 
as the VA. ${ }^{20}$ Veterans may file disability claims for physical or psychological disabilities or a combination of both. ${ }^{21}$ "Disability Compensation is a tax free monetary benefit paid to Veterans with disabilities that are the result of a disease or injury incurred or aggravated during active military service." 22

Benefits compensating a veteran for a disability connected to military service are called "service-connected disability compensation benefits." 23 Eligible applicants can receive serviceconnected disability compensation benefits through the serviceconnected disability compensation program, one of the VA's two major benefits programs. ${ }^{24}$

To show basic entitlement to service-connected disability compensation, a veteran must demonstrate that:

(1) [the veteran was] discharged or released under conditions other than dishonorable [discharge or release],

(2) [the veteran's] disease or injury was incurred or aggravated in the line of duty, and

20. 38 U.S.C. $\S 101(2)$ (2006); 38 C.F.R. $§ 3.1(d)$ (2011). The definition of "veteran" is "a person who served in the active military, naval, or air service, and who was discharged or released therefrom under conditions other than dishonorable." See also VeterAns BenEFITS MANUAL, supra note 1, at 23-25.

21. A psychological disability claim may be referred to in the VA as a "nervous condition" claim. See Veterans Benefits MANUAL § 3.5.1 155 (2011). The authors of the Veterans BEnEFITS MANUAL note the VA often calls mental disorders "nervous conditions" because of the perception that terms like "psychosis, paranoia, or dementia . . . might be offensive." See Veterans BenEfits Manual, supra note 1 , at 155 , note 665 .

22. VA Disability Compensation, U.S. DEP'T VETERANS AFF. http://www.vba.va.gov/bln/21/compensation/index.htm (last visited June 14, 2013).

23. VETERANS BeNEFITS MANUAL, supra note 1 , at 53.

24. Veterans Benefits Manual, supra note 1, at 53. The other major benefits program is the non-service-connected disability pension program. Substantially more veterans receive compensation benefits that pension benefits; in fiscal year 2010, 3,181,700 veterans were receiving compensation benefits, yet only 310,200 veterans were receiving pension benefits. VETERANS BENEFITS MANUAL, supra note 1 , at 53 . 
(3) the disability is not a result of [the veteran's] own willful misconduct or abuse of alcohol or drugs. $^{25}$

If the veteran shows basic entitlement, the veteran must prove the elements for service-connected disability compensation: "a diagnosis of current disability; evidence of in-service occurrence or aggravation of a disease, injury, or precipitating event; and competent evidence of a link or nexus between the inservice occurrence or aggravation of a disease or injury and the current disability." 26

If the veteran satisfies the requirements for compensation, the VA will send the veteran a monthly payment based upon his or her "disability "rating." 27 The rating represents an amount the "average citizen" would be impaired by or limited from earning income by the same disability the veteran has. ${ }^{28}$ "Each disability must be considered from the point of view of the veteran working or seeking work." 29 If the entire record ${ }^{30}$ results in a reasonable doubt as to the degree of disability, the VA will resolve the doubt in favor of the veteran. ${ }^{31}$

25. Veterans Benefits ManUal, supra note 1, at 53 (citing 38 U.S.C.S. $\S \S$ 101(2), 1110, 1131; 38 C.F.R. $§ 3.12$, 3.4(b)(1), 3.301); 38 U.S.C. $§ 101(16)$ (2006); 38 C.F.R. § 3.1(k) (2011); see also 38 C.F.R. § 3.303(a) (2011) ("Service connection connotes many factors but basically it means that the facts, shown by evidence, establish that a particular injury or disease resulting in disability was incurred coincident with service in the Armed Forces, or if preexisting such service, was aggravated therein.").

26. VETERANS BENEFITS MANUAL, supra note 1, at 152.

27. Veterans Benefits Manual, supra note 1, at 54. This monthly disability payment may be increased for a variety of reasons, including if the veteran has a severe disability, qualifying family members, or has special health care or other needs due to severe disabilities. VETERANS BENEFITS MANUAL, supra note 1, at 54.

28. 38 C.F.R. $§ 4.1$ (2011) ("The percentage ratings represent as far as can practicably be determined the average impairment in earning capacity resulting from such diseases and injuries and their residual conditions in civil occupations").

29. 38 C.F.R. $\S 4.2(2011)$.

30. 38 C.F.R. $\S 4.3$ (2011); 38 C.F.R. $§ 3.102$ (2011). Section 4.2 requires a rating specialist to review and reconcile "the whole recorded history."

31. See Veterans Benefits Manual, supra note 1, at 1001. 
Currently, a veteran with no spouse or children who is rated $100 \%$ disabled would receive $\$ 2,816$ per month, or $\$ 33,792$ per year in disability compensation. ${ }^{32}$

If a veteran disagrees with the VBA rating specialist's decision, the veteran may appeal that decision in a variety of ways, including to the Board of Veterans' Appeals (BVA), which is the second level of review after the VBA Regional Office where the rating specialist is located. ${ }^{33}$ The Veterans' Judicial Review Act of 1988 (VJRA) established an Article I court, the United States Court of Appeals for Veterans Claims (CAVC), to review BVA decisions; it also provided for limited review of CAVC decisions in the Federal Circuit. ${ }^{34}$

\section{B. The Compensation \& Pension Examination}

After a veteran submits a disability claim to the Veterans Benefits Administration (VBA), the veteran is usually required to submit to a medical examination called a Compensation \& Pension Examination (C\&P Examination). ${ }^{35}$ This examination is most often performed by a physician in the Veterans Health Administration (VHA). ${ }^{36}$ The VBA will rely heavily on the C\&P Examination report in determining how to rate the veteran's disability.

A VBA ratings specialist will request a C\&P Examination from the VHA when he is trying to identify a veteran's disability or determine the extent to which a veteran is disabled. In the request, the VBA will list specific disabilities or complaints and symptoms that may be tied to specific disabilities; the C\&P examiner must address each listed disability, complaint, or

32. Veterans Compensation Benefits Rates Tables, supra note 5. This amount may be increased by a variety of additional payments depending on the veteran's employability, family situation, and the context of the veteran's service. For example, a veteran who is considered $100 \%$ disabled and has a spouse and one child would receive $\$ 3,088$ per month in disability compensation.

33. See VHA Handbook 1601E.01: Compensation \& Pension (C\&P) Examinations, U.S. DEP'T VETERANS AFF., http://www.va.gov/vhapublications/View Publication.asp?pub_ID=2094 (last visited June 14, 2013).

34. See VETERANS BENEFITS MANUAL, supra note 1, at 1113-15.

35. See VHA Handbook 1601E.01, supra note 33.

36. See VHA Handbook 1601E.01, supra note 33, at 1. Depending on the circumstances of the case and how the report is presented, a private physician's report may be accepted in lieu of a VHA physician's report. However, the vast majority of claims for disability compensation must be supported by a C\&P Examination performed by a VHA physician. 
symptom in the report, providing either a diagnosis or a statement that no disability or chronic illness was found connected to the listed complaint or symptom. ${ }^{37}$

The VBA may request a C\&P Examination if the veteran claimant has already been diagnosed with a disability, but the disability has not been rated. ${ }^{38}$ The rating specialist will then use the report to match the veteran's symptoms with diagnostic criteria to determine the veteran's disability rating. ${ }^{39}$ Another context when the C\&P Examination becomes a factor is if the veteran has submitted a disability claim but has no current diagnosis, or the current diagnosis has yet to be tied to an event, injury, or disease from the veteran's military service. ${ }^{40}$ The VBA may also request a C\&P Examination if it needs further medical evidence to determine whether the veteran is basically entitled to disability compensation. $^{41}$

When the C\&P Examination is being requested for diagnosis or rating of a psychological disability, the VHA psychiatrist must include specific information in addition to the general evaluative information required for any $\mathrm{C} \& \mathrm{P}$ report. The psychiatrist must provide "[a]n up-to-date brief psychiatric and psychosocial history." 42 The psychiatrist must also provide a "5axis diagnosis utilizing the most recent Diagnostic and Statistical Manual (DSM). ${ }^{43}$ The five different axes in DSM-IV are:

Axis I refers to "Clinical Disorders" such as anxiety or schizophrenia and also "Other Conditions That May Be a Focus of Clinical Attention" such as alcohol abuse;

37. See VHA Handbook 1601E.01, supra note 33, at 4 .

38. See 38 C.F.R. § 3.326 (2011); VHA Handbook 1601E.01, supra note 33, at 2 .

39. See Veterans Benefits Manual, supra note 1, at 302-03 (generally discussing how medical examinations are used to determine the degree of disability).

40. See VHA Handbook 1601E.01, supra note 33, at 2.

41. See VHA Handbook 1601E.01, supra note 33, at 2. This third reason acts as a catchall for the various reasons the VBA may need an examination to determine a claim.

42. See VHA Handbook 1601E.01, supra note 33, at 4.

43. See VHA Handbook 1601E.01, supra note 33, at 4-5. The VHA Handbook notes that a mental health diagnosis is complete only if it is "multi-axial." 
Axis II refers to "Personality Disorders" and "Mental Retardation";

Axis III refers to "General Medical Conditions" such as diabetes or a heart condition;

Axis IV refers to "Psychosocial and Environmental Problems" such as educational problems, financial problems, unemployment; and

Axis V refers to "Global Assessment of Functioning" (GAF) which is a numerical assessment, on a scale of 1 to 100 , of the patient's overall psychological, social, and occupational functioning. ${ }^{44}$

The different axes were developed to help a clinician organize the various difficulties a patient may be experiencing along with psychiatric symptoms.

\section{Rating a Veteran's Psychological Disability}

The VBA gatekeeper, called a rating specialist, will evaluate a veteran's claim for a "mental disorder," or psychological disability, using the schedule of ratings for mental disorders found at 38 C.F.R. $\S 4.130$. The schedule of ratings for mental disorders is based on the DiagnOSTIC AND STATISTICAL Manual of Mental Disorders, Fourth Edition, of THE AMERICAN PSYCHIATRIC AsSOCIATION (DSM-IV). ${ }^{46}$ Section 4.130

44. See Veterans Benefits ManUal, supra note 1, at 155 (citing American Psychiatric Association, Diagnostic and Statistical Manual of MENTAL Disorders 25 (4th ed. 1994) (DSM-IV)).

45. See Veterans Benefits Manual, supra note 1, at 155 (describing the multiple axes as "a simple way of organizing, for treatment purposes, the many problems that one person may be experiencing at the same time").

46. 38 C.F.R. $\S 4.130$ (2011); see also 38 C.F.R. $\S$ 4.125(a) (2011) (providing that "if the diagnosis of a mental disorder does not conform to DSM-IV . . . the rating agency shall return the report to the examiner to substantiate the diagnosis"). The Fifth Edition of the DSM, called DSM-5, was recently released in May 2013. See American Psychiatric Association DSM-5 Development, http://www.dsm5.org/Pages/Default.aspx (last visited June 14, 2013). This may mean the VA will soon transition to using DSM-5; however, until the applicable regulations, including 38 C.F.R. $\S \S 4.130$ and 4.125 are updated to require 
directs rating agencies to be "thoroughly familiar" with the DSMIV in order to apply the general rating formula for mental disorders. $^{47}$

A VA rating specialist must evaluate several categories of evidence when rating a mental disorder:

(1) the frequency of the veteran's psychiatric symptoms;

(2) the severity of the veteran's psychiatric symptoms;

(3) how long the veteran's psychiatric symptoms have lasted;

(4) the length of remissions, if any, in the veteran's psychiatric symptoms; and

(5) the "veteran's capacity for adjustment" during the times the veteran has been in remission. ${ }^{48}$

As with physical disabilities, the rating specialist's focus will be on how much the disability limits the veteran's ability to earn income. ${ }^{49}$ In particular, the rating specialist will look for evidence relating to "occupational impairment" and "social impairment."

A rating specialist will place great weight on the C\&P Examination report prepared by a VHA psychiatrist. Although the rating specialist may also consider "lay" evidence, including statements from the veteran's family, friends, work supervisors and co-workers, the C\&P Examination is considered an expert opinion that carries greater weight, in most cases, than lay opinions. ${ }^{51}$ In

application of DSM-5, the DSM-IV remains the authority for rating mental disorders in VA compensation claims.

47. 38 C.F.R. $\S 4.130$ (2011).

48. 38 C.F.R. $\S 4.126(a)(2011)$.

49. 38 C.F.R. $\S 4.126$ (a) (2011)

50. 38 C.F.R. $\S 4$ 4.126(a) (2011). In evaluating mental disorders, the "extent of social impairment" is a specific consideration; however, a rating specialist may not rest an evaluation solely on the extent of the veteran's social impairment. See 38 C.F.R. $\S 4.126($ b) (2011).

51. In Nieves-Rodriguez v. Peake, 22 VET. ApP. 295 (2008), the United States Court of Appeals for Veterans Claims examined the practice of evaluating 
addition, the rating specialist may consider, if it has sufficient foundation, a medical opinion from a private (non-VA) doctor. ${ }^{52}$

\section{CUlture AND Mental Health}

\section{A. The Intersection of Culture and Mental Health Generally}

Culture can carry different meanings in different contexts, ${ }^{53}$ but one common definition is "a set of meanings, behavioral norms, values and practices used by members of a particular society, as they construct their unique view of the world." ${ }^{, 54}$ It is

medical opinions in determining a veteran's disability rating. The Court explained that both a VA physician's opinion (like a private physician's opinion) is "nothing more or less than [an] expert witness [] report" in a disability benefits case and appeal. Id. at 302. The Court identified the factors in Federal Rule of Evidence 702 as "guiding factors to be used by the Board in evaluating the probative value of medical opinion evidence." Id.

52. Id. (noting a private medical expert may submit an opinion with proper foundation if the expert "is informed of sufficient facts upon which to base an opinion relevant to the problem at hand"). The Court in Nieves-Rodriguez noted that the VA physician typically reviews, in preparation for the C\&P examination, the veteran's "claims file" or "C-file," which includes "all documents associated with a veteran's disability claim, including not only medical examination reports and [service medical records], but also correspondence, raw medical data, financial information, rating decisions of VA regional offices, Notices of Disagreement, such materials pertaining to claims for conditions not currently at issue and, often, Board decisions disposing of earlier claims." Id. at 301. The veteran in that case argued that the VA was required to provide every physician with the C-file before an examination, but the Court held that the file "is not a magical or talismanic set of documents, but rather a tool to assist VA examiners to become familiar with the facts necessary to form an expert opinion to assist the adjudicator in making a decision on a claim." Id. at 302-303. The Court acknowledged that a private physician may either review the C-file or obtain "critical medical facts" through other means, and it gave the example of a private physician who has become knowledgeable in the veteran's complete medical history by "treating the claimant for an extended period of time." Id. at 303.

53. Susan Bryant, the author of The Five Habits: Building Cross-Cultural Competence in Lawyers, 8 CLINICAL L. REV. 34, 40 (2001-2002), advocates for a broad definition of culture in the context of developing cross-cultural lawyering. She writes, "[c]ulture is like the air we breathe - it is largely invisible and yet we are dependent on it for our very being. . . . We are constantly attaching culturally-based meaning to what we see and hear, often without being aware that we are doing so."

54. Juan E. Mezzich, Giovanni Caracci, Horacio Fabrega, Jr. \& Laurence J. Kirmayer, Cultural Formulation Guidelines, 46 TrAnscultural PSYCHIATRY 383, 384 (2009) (emphasis added); see also Sussie Eshun \& Regan A.R. Gurung, 
both learned and distinctive, and it impacts "how we think, how we respond to distress, and how comfortable we are expressing our emotions." ${ }^{, 5}$ Not surprisingly, then, culture has been found to impact a person's psychological identity and experience in a variety of ways, including how an individual experiences mental illness and tells others about symptoms of mental illness, how a clinician interprets an individual's symptoms, and a clinician's treatment plan for an individual with mental illness. ${ }^{56}$ In addition, culture may affect an individual's decision to seek help from mental health professionals in the first place. ${ }^{57}$

Although not wholly dependent on how a patient reports symptoms, psychological measurements are inevitably influenced by the patient's description of symptoms. ${ }^{58}$ A 2001 Surgeon General's report on culture and mental health acknowledged that " $[t]$ he diagnosis and treatment of mental disorders depend to a large extent on verbal communication between patient and clinician about symptoms, their nature, intensity, and impact on functioning." 59 Some researchers describe psychiatric assessment as "an interpretation of an interpretation," the first critical level of interpretation being the patient's own translation of feelings, thoughts, and physical symptoms into words. ${ }^{60}$ A patient's cultural identity and background can "profoundly affect[] how medical and

Introduction to Culture and Psychopathology, in Culture AND Mental Health: Sociocultural Influences, Theory, \& Practice 3 (Sussie Eshun \& Regan A.R. Gurung eds., 2009) (discussing several definitions of "culture").

55. Eshun \& Gurung, supra note 54, at 4.

56. Id. at $4-5$.

57. Id. at 6.

58. Peter D. Yeomans \& Evan M. Forman, Cultural Factors in Traumatic Stress, in Culture And Mental Health: Sociocultural Influences, Theory, \& Practice 230-31 (Sussie Eshun \& Regan A.R. Gurung eds., 2009) (discussing contextual and cultural factors in how trauma symptoms are reported).

59. Dep't Health \& Human Servs., Mental Health: Culture, Race, and Ethnicity: A Supplement to Mental Health: A Report of the Surgeon General 31 (U.S. PubliC HeAlth SERviCe, 2001), available for download at NCBI, http://www.ncbi.nlm.nih.gov/books/NBK44243/.

60. Michelle Christensen, Diagnostic Criteria in Clinical Settings: DSM-IV and Cultural Competence, 10(2) Am. Indian \& AlASKA NATIVE MENTAL HeAlth RESEARCH 52 (2001), available at CENTER FOR AMERICAN INDIAN \& ALASKA Native Mental Health, Colorado School of Public Health, http://www.ucdenver.edu/academics/colleges/PublicHealth/research/centers/CAIAN H/journal/Documents/Volume\%2010/10\%282\%29.pdf (last visited June 14, 2013). 
mental illnesses are described." 61 And when the patient's translation includes descriptions that don't easily fit into the universal diagnostic criteria for a psychological condition, the patient's symptoms may be mis-measured and the patient inaccurately diagnosed. One example from the DSM-IV is that, while universal diagnostic criteria for major depression focus on mental symptoms, some cultures have been found to describe symptoms of depression using primarily somatic, or physical, complaints. ${ }^{62}$ Another even more specific example comes from the American Indian Hopi tribe; Hopi suffering from major depression have consistently reported being "heartbroken," which is not easily translated into any single criterion in the dominant checklist for major depression. ${ }^{63}$

In addition to influencing particular words a person uses to describe psychological distress, culture may influence the symptoms a person actually admits. Some researchers refer to this as the "social desirability" factor, and describe patients reporting or failing to report symptoms based on their perception of what is socially desirable within their cultures. ${ }^{64}$

61. Richard G. Dudley, Jr. \& Pamela Blume Leonard, Getting it Right: Life History Investigation as the Foundation for a Reliable Mental Health Assessment, 36 Hofstra L. ReV. 963, 967-68 (2008) (discussing the use of a "mitigation specialist" in capital defense work to explore a defendant's culture, among other factors, and how that culture impacts the defendant's description and experience of mental illness).

62. Christensen, supra note 60 at 53.

63. Id. In Diagnostic Criteria in Clinical Settings, Christensen demonstrates that the way a patient translates distress could result in misdiagnosis and ineffective treatment. Her fictitious patient (based on a composite of many American Indian patients suffering from depression) was an enrolled member of the Northern Plains tribe who described being "bored" and "angry." According to the dominant DSM-IV symptom cluster for major depression, the patient may not have been diagnosed with major depression based on this description. But Christensen showed how, if evaluated in cultural context, the patient's description could be translated into the dominant criterion of "loss of pleasure or interest" corresponding to major depression. By exploring the patient's interaction with her community on the Northern Plains reservation, including struggles in her relationships and internal conflict regarding whether to leave the reservation, Christensen showed she may ultimately determine whether the patient was generally bored or whether "boredom" actually described a symptom of depression in the patient's cultural context.

64. Yeomans \& Forman, supra note 58, at 232 ("Cultures vary in the extent to which expression of distress is socially sanctioned and reported."); see also Yeomans \& Forman, id., at 230 ("Even a carefully translated and then validated 
The real potential for injustice comes when patients whose cultures heavily influence the way they communicate distress meet clinicians who use a universalist or one-size-fits-all approach to assessment and diagnosis. As a patient may report symptoms differently across cultures, a clinician may interpret what the patient reports differently depending on the clinician's approach to assessment and diagnosis. ${ }^{65}$ The effect is even more significant when the patient and the clinician are from different cultures. The Surgeon General's report on culture and mental health points out:

The emphasis on verbal communication yields greater potential for miscommunication when clinician and patient come from different cultural backgrounds, even if they speak the same language. Overt and subtle forms of miscommunication and misunderstanding can lead to misdiagnosis, conflicts over treatment, and poor adherence to a treatment plan. ${ }^{66}$

A clinician's assessment of a patient may not be as accurate unless the assessment instrument used was either specifically designed to measure a particular symptom in that veteran's culture or was proven to be conceptually equivalent across cultures. ${ }^{67}$

Concepts such as anxiety, depression, aggression, anger, intrusive thoughts, and emotional numbing are central to understanding the psychological response to high-magnitude stressors. These characteristics have different meanings, and their

measure is still subject to an effect of social desirability in which participants' responses are influenced by their perceptions of what a favorable answer might be.").

65. Mezzich, Caracci, Fabrega, Jr. \& Kirmayer, supra note 54 at 384. This would be the second level of interpretation discussed by Michelle Christensen in Diagnostic Criteria in Clinical Settings, supra note 60, at 52-53 ("The second level of interpretation is the process by which a clinician . . . translates a client's translation of his/her internal experience into the language of psychiatry.").

66. See Dep't Health \& Human Servs., supra note 59, at 32.

67. Terence M. Keane, Danny G. Kaloupek \& Frank W. Weathers, Ethnocultural Considerations in the Assessment of PTSD, in ETHNOCULTURAL Aspects of Posttraumatic Stress Disorder: Issues, Research, \& Clinical AppliCAtions 188 (Anthony J. Marsella ed., 1996). 
presence has different implications for societies the world over. To assume cross-cultural conceptual equivalence of items measuring these constructs and symptoms surely would lead to mis-measurement of the important concepts related to traumatization in different societies. ${ }^{68}$

A clinician who assesses a patient while ignoring that patient's unique cultural identity risks providing an incomplete picture of the severity of the patient's illness. ${ }^{69}$ Experts in psychometrics, the science of measuring psychological symptoms, agree that most psychological conditions have some universal components that a person will exhibit regardless of cultural background. ${ }^{70}$ However, if a clinician focuses on only those universal components without regard to potential influence of culture, the clinician's error could be disastrous for the individual patient. ${ }^{71}$ In the veterans' disability claim context, the veterans are relying on accurate diagnosis not only as a guide for effective treatment, but also as the foundation for accurate disability ratings, something many of them rely on as a major part of their income. ${ }^{72}$

Clinicians familiar with variations across and within different cultural groups are better equipped to spot potential factors relevant to diagnosis of clients from those groups. ${ }^{73} \mathrm{~A}$ clinician's diagnosis is considered "culturally competent," and therefore more accurate, if the clinician used accepted methods to account for the patient's cultural and ethnic background. ${ }^{74}$ This is known as "culturally-informed diagnosis.,"75

68. Id. at 188 .

69. Id. at 186.

70. Bonnie A. Green, Culture \& Mental Health Assessment, in CulturE AND Mental Health: Sociocultural Influences, Theory, \& Practice 22-23 (Sussie Eshun \& Regan A.R. Gurung eds., 2009).

71. Roberto Lewis-Fernandez, The Cultural Formulation, 46 TRANSCUlTURAL PSYCHIATRY 379, 380 (2009).

72. See Green, supra note70, at 23 ("A test that fails to properly diagnose a person with depression will result in a person being left untreated with the consequences that follow[].”).

73. Freddy A. Paniagua, Diagnosis in a Multicultural ConteXt 3-13 (2001).

74. Mezzich, Caracci, Fabrega, Jr. \& Kirmayer, supra note 54, at 384.

75. Id. at 384 . 
Ideally, the variations form a foundation for more informed diagnosis rather than a box within which a clinician places a minority client. ${ }^{76}$ For example, a clinician may be aware that American Indian fathers or elders often take the role of family administrator rather than "head" or "authority," and encourage young people within the community to make their own decisions. ${ }^{77}$ The clinician starting from this place of understanding may explore whether this client's unique experience within his community or tribe places him in a role of independence and mutual respect rather than submission to an authoritarian figure. ${ }^{78}$ This may then be relevant in exploring the client's psychology within his family and community and whether external pressures contribute to the client's symptoms. $^{79}$

76. Mezzich, Caracci, Fabrega, Jr. \& Kirmayer, supra note 54, at 393 ("Stereotyping provides a simplistic and distorted picture of the social and individual aspects of a person and in itself can have negative consequences for mental health."); see also Dep't Health \& Human Servs., supra note 59, at 25-26 ("[G]eneral statements about cultural characteristics of a given group may invite stereotyping of individuals based on their appearance or affiliation. Because there is usually more diversity within a population than there is between populations (e.g., in terms of level of acculturation, age, income, health status, and social class), information [in the report] should not be treated as stereotypes to be broadly applied to any individual member of a racial, ethnic, or cultural group.").

77. PaniaguA, supra note 73, at 6 ("Contrary to the Asian and Hispanic families, in American Indian families, the father (or older adult) only administers the family; he does not control the family in the sense of being authoritarian or macho.").

78. Id. at 6. Paniagua describes the difference between the authoritarian figures often seen in Asian families with the administrative figures often seen in American Indian families. Instead of submission to authority, American Indian families tend to value and reward mutual respect among family and tribal members. "Strong family relationship is emphasized, but a sense of independence among family members is rewarded, particularly among American Indian children and adolescents." $I d$. at 6 .

79. Another example is the veteran whose ongoing depression has caused the veteran to lose touch with many family members and isolate himself or herself, but who answers the examiner's questions about close relationships by describing one close relationship the veteran has been able to maintain. If the examiner is unaware that the veteran's cultural norms place great emphasis on community, the examiner may report that the veteran has been able to maintain close relationships and shows little social impairment, a factor in determining the severity of psychological disabilities like post-traumatic stress disorder (PTSD). The veteran's single close relationship is more likely evidence the veteran is isolated from the majority of family and community in a way that may be indicative of significant social 


\section{B. The DSM-IV Cultural Formulation Outline}

The good news is that the DSM-IV already includes a mechanism through which both VA psychiatrists and private psychiatrists can account for cultural factors in a patient's psychological disability. Previous editions of the DSM had little cultural sensitivity, but DSM-IV recognizes the importance of a patient's culture to a clinician's diagnosis of psychiatric disorders and provides an outline with which a clinician can construct a complete disability picture including appropriate cultural context. ${ }^{80}$ It also describes potential cultural variations for many specific psychiatric disorders. ${ }^{81}$

The DSM-IV Cultural Formulation Outline, a copy of which is reprinted in Appendix A, guides a clinician through an exploration of a patient's cultural identity, including the cultural reference group, language, and other factors in development,

impairment in the veteran's communal culture. See Aaron P. Jackson \& Sherri Turner, Counseling \& Psychotherapy with Native American Clients, in PRACTICING Multiculturalism: AfFirming Diversity in COUnSEling AND PSYCHOlogy 227 (Timothy B. Smith ed., 2004) (noting, for example, that American Indian communities, although the many independent tribes have different values and belief systems in the specific, are often more "communal" than individualistic majority European American communities).

80. See Christensen, supra note 60, at 52 ("DSM-IV now includes a structured outline for gathering such culturally relevant information that encourages clinicians to gather this information more routinely, and provides a systematized means of doing so."); Spero M. Manson, Mental Health Services for American Indians \& Alaska Natives: Need, Use, and Barriers to Effective Care, 45 CAN. J. PSYCHIATRY 617, 618 (2000) ("The DSM-IV marks a dramatically new level of acknowledgment of culture's role in shaping the symptoms, expression, and course of major mental illness."). The new DSM-5 promises even greater cultural sensitivity than the DSM-IV: "Rather than a simple list of culture-bound symptoms, DSM-5 updates criteria to reflect cross-cultural variations in presentations, gives more detailed and structured information about cultural concepts of distress, and includes a clinical interview tool to facilitate comprehensive, person-centered assessments." American Psychiatric Publishing, DSM-5 Fact Sheets, Cultural Concepts in DSM-5, http://www.psychiatry.org/DSM5 (last visited June 14, 2013).

81. Although DSM-IV does not systematically cover cultural variations for every psychiatric disorder, it covers many of the psychiatric disorders prevalent among veterans who have disorders related to trauma. See Christensen, supra note 60, at 14-15, 17-18 \& Table 2.1 (Summary of Psychiatric Disorders with Descriptions of Cultural Variations in the DSM-IV, listing PTSD, Generalized Anxiety Disorder, Major Depressive Disorder, and all subtypes of Adjustment Disorder). 
involvement with the culture of origin and with the "host" culture. ${ }^{82}$ Next the clinician explores cultural explanations of the veteran's illness, including predominant idioms of distress and local illness categories, the meaning and severity of symptoms in relation to cultural norms, perceived causes and explanatory models, and help-seeking experiences and plans. ${ }^{83}$ Finally, the clinician explores any cultural factors related to the patient's psychosocial environment and levels of functioning, including social stressors and social supports, and any cultural elements of the clinicianpatient relationship. ${ }^{84}$

The purpose of the Cultural Formulation Outline is to guide a clinician through a comprehensive evaluation sensitive to the individualized meaning of the patient's symptoms. ${ }^{85}$ A clinician's use of the Cultural Formulation Outline will result in a "more thorough evaluation" of the patient's unique illness and the severity of the patient's symptoms. ${ }^{86}$ In contrast, when a busy clinician does not explore a patient's "sociocultural context" and take a more idiographic (individualized), rather than nomothetic (decontextualized), approach to the initial assessment, the resulting assessment and diagnosis may not accurately calibrate the severity of the patient's symptoms. ${ }^{87}$

The bad news is that, despite its importance to accurate diagnosis of patients with diverse cultural backgrounds, the DSMIV Cultural Formulation Outline is not widely used by clinicians. Even clinicians' "awareness of the availability of the Cultural Formulation has remained limited." 88 Proponents of the Cultural Formulation criticized its placement in the Appendix rather than

82. See Christensen, supra note 60 , at 18-20.

83. See id.at 20.

84. See id.at 20-24; see also Theresa D. O'Nell, Cultural Formulation of Psychiatric Diagnosis: Psychotic depression and alcoholism in an American Indian man, 22 Culture, Medicine \& Psychiatry 123 (1998).

85. See Lewis-Fernandez, supra note 71, at 380 ("The point of the Cultural Formulation is precisely that it asks clinicians to operationalize a more thorough evaluation of the sociocultural context in which illness experience is embedded.").

86. See id.

87. See id. ("Without this systematic contextual assessment, the meaning of much of patients' illness behavior-including valid calibration of their symptom severity - may elude a busy provider, increasing the risk of clinical mismanagement and of patient dissatisfaction, nonadherence, and poor treatment response.").

88. Mezzich, Caracci, Fabrega, Jr. \& Kirmayer, supra note 54, at 385. 
the main axes of DSM-IV, predicting clinicians may be less aware it existed in the back of the manual. ${ }^{89}$ Studies have shown that even clinicians who are aware of the Cultural Formulation may not use it in practice because of the time it takes during an initial assessment. ${ }^{90}$ In addition, clinicians may believe accounting for cultural variables adds a layer of complexity to the diagnostic process that "might seem only to complicate an already arduous task" of formulating a patient's case. ${ }^{91}$ In fact, observations of groups of clinicians who are aware of the Cultural Formulation Outline in the DSM-IV show it is underutilized in initial client evaluations. $^{92}$

The main goal of psychiatric diagnosis is to make a patient's clinical care more effective. With effective treatment as the end goal, a clinician explores a patient's cultural and ethnic background and experiences to encourage "an effective and helpful doctor-patient relationship." "Beyond issues of reliability, cultural factors play a central role in the validity and usefulness of diagnosis to fulfill its key purpose - the optimization of clinical care." "94 Experts in DSM-IV's Cultural Formulation Outline contemplate a comprehensive evaluation of a patient's social and cultural "identity" 95 that includes more than just one patient

89. See Christensen, supra note 60 , at 18 (" $[\mathrm{P}]$ lacing the Cultural Formulation in Appendix I would suggest to many clinicians that they are not required to consider cultural variants during the assessment of the case using the $D S M-I V . ")$.

90. See Lewis-Fernandez, supra note 71, at 379-80.

91. Lisa R. Fortuna, Michelle V. Porche \& Margarita Alegria, A Qualitative Study of Clinicians' Use of the Cultural Formulation Model in Assessing Posttraumatic Stress Disorder, 46(3) Transcultural Psychology 429, 443 (2009).

92. See id. at 445 ("While it is highly encouraging that clinicians are willing to consider culture, it is also clear that the components of the Cultural Formulation are generally underutilized or used inconsistently in the initial evaluation.").

93. Mezzich, Caracci, Fabrega, Jr. \& Kirmayer, supra note 54, at 384.

94. Id.

95. In the context of transcultural psychiatry, social and cultural "identity" is defined as: "(1) the patient's conception of their place in the world in which they live (e.g., their location in the network of roles and relationships that make up their personal, social and spiritual world) and (2) the meaning, rationale, or mode of operation of the world, the self, other and persons in general (e.g., the ideas, concepts, values or doctrines that make the patient's world a meaningful one to 
interview. ${ }^{96}$ After a clinician interviews the patient, the next source of relevant cultural information is the patient's family, then others familiar with the patient's culture, and finally even further exploration of background information about the patient's culture. $^{97}$

This comprehensive evaluation is crucial to the clinician's understanding of how to manage the patient's condition through treatment. ${ }^{98}$ A clinician typically uses all of the information gathered during an assessment to diagnose and move into further treatment. "Performing a cultural formulation of illness requires of the clinician to translate the patient's information about self, social situation, health, and illness into a general biopsychosocial framework that the clinician uses to organize diagnostic assessment and therapeutics." 99 In this way, the Cultural Formulation Outline is designed to have "practical value.",100

In the civilian world, a clinician looks at diagnosis with treatment and a patient's improved functionality as the main objective; the clinician and patient are often developing a longterm relationship. But, in the VA disability system, clinicians are required to diagnose for a different reason. A VA psychiatrist's diagnosis will either support or defeat a veteran's application for disability compensation. As with other administrative inquiries, "[a] favorable review leads to the disbursement of cash or other benefits." 101 The VA psychiatrist is therefore diagnosing the

them); and the symbolic systems and meanings that the patient uses in relation to specific communities, nations of origin, or ethnic groups." Id. at 390-91.

96. Id. at 391 .

97. Id.

98. See Lewis-Fernandez, supra note 71, at 379-80.

99. Mezzich, Caracci, Fabrega, Jr. \& Kirmayer, supra note 54, at 391.

100. See Lewis-Fernandez, supra note 71, at 379-80 ("[A] long and complex Cultural Formulation that is mainly of scholarly interest and will not be implemented in actual practice is of little practical value.").

101. See Harvey D. Lomas \& Jonathan D. Berman, Diagnosing for Administrative Purposes: Some Ethical Problems, 17(4) SoC. SCI. MED. 241, 241 (1983). Veterans who are found to have service-connected disabilities may also be eligible for housing and insurance benefits, like adapted housing grants and mortgage life insurance. See Compensation, U.S. DEP'T VETERANS AFF., http://www.benefits.va.gov/compensation/ (last visited June 13, 2013). 
veteran for an administrative purpose rather than a therapeutic purpose. $^{102}$

Since a clinician may not be considering treatment and improved functionality during the isolated initial assessment, the question becomes what role the Cultural Formulation takes in this context. The Cultural Formulation is designed to be a narrative, individualized assessment of a patient exploring the unique context within which that patient experiences psychological distress. This is all done with "accountability" to the patient who will presumably continue in treatment and expect therapeutic progress. ${ }^{103}$ Because the VA psychiatrist in a C\&P Examination is diagnosing for administrative purposes, the Cultural Formulation would be relevant to that psychiatrist only to the extent it may impact the information used to complete the C\&P claims process.

However, even though VA Compensation and Pension examiners are not likely to continue treating a veteran, the Cultural Formulation Outline will lead to a more comprehensive and accurate diagnosis during a C\&P Examination. It has the potential to change or significantly impact the examiner's application of the DSM-IV diagnostic criteria. This, in turn, might change the disability rating a VBA gatekeeper assigns based on the examiner's diagnosis. If it results in a more accurate initial rating, it could help a veteran avoid a lengthy appeal process. ${ }^{104}$ In

102. See Lomas \& Berman, supra note 101, at 241-42 (acknowledging the differences between a physician's diagnosis for therapeutic reasons and a physician's diagnosis for purposes of disbursing public funds).

103. See id. at 242 (noting that diagnosis for administrative purposes lacks "therapeutic intent and accountability").

104. The VBA Transparency Program, known as "ASPIRE," shows the VBA takes, on average, 275.7 days to complete a compensation claim that requires a disability rating. See ASPIRE-Benefits, U.S. DEP'T OF VETERANS AFF., available at http://www.app.hospitalcompare.va.gov/index.cfm (last visited June 14, 2013). The Board of Veterans Appeals' Annual Report to Congress in 2011 showed the average time between filing an appeal with the Board and the Board's ultimate disposition of the appeal was 883 days. See Report of the Chairman, BD. OF VetERANS APPEALS, 18, available at http:/www.bva.va.gov/docs/Chairmans_Annual_Rpts/BVA2011 AR.pdf (last visited June 14, 2013). If a claim is sent back to the VA, the Appeals Management Center takes, on average, 248.6 days to complete the claim. See ASPIRE-Benefits, U.S. DEP'T OF VETERANS AFF., available at http://www.app.hospitalcompare.va.gov/index.cfm (last visited June 14, 2013). Adding each of these phases results in an over four-year process to reach a final decision on an appealed and remanded compensation claim. 
addition, it may contribute information relevant to a patient's further treatment, including the doctor-patient relationship between the veteran and future treating doctors in the VA healthcare system. So it is vitally important for an advocate to press for a culturally-informed diagnosis in the early stages of a veteran's claim that will lead to an appropriate disability rating and subsequent treatment plan. Alternatively, an advocate who enters a veteran's disability claim at a later stage or on appeal should press for a culturally-informed review of the entire mental health record that will lead to either a reopened claim or an increased disability rating that more appropriately compensates the veteran.

\section{Culture and Mental Health at the VA}

Researchers have long urged VA Compensation and Pension examiners to use culturally-informed clinical assessment procedures that fully explore potential cultural factors in psychological disabilities. ${ }^{105}$ One of the disabilities most prevalent among combat veterans, Posttraumatic Stress Disorder (PTSD), is a combination of psychological symptoms associated with exposure to trauma, including witnessing or surviving violence. ${ }^{106}$ Researchers have repeatedly emphasized that concepts related to major trauma can carry different meaning across groups. ${ }^{107}$ Nearly twenty years ago, the National Center for Post-Traumatic Stress Disorder, a research facility within the Department of Veterans Affairs, discovered a higher incidence of PTSD among ethnocultural minorities, as well as cultural variations in the way veterans express symptoms of PTSD and other anxiety and depressive disorders. ${ }^{108}$ VA researchers noted data showing

105. Anthony J. Marsella, Claude Chemtob \& Roger Hamada, Ethnocultural Aspects of PTSD in Vietnam War Veterans, 1(2) Nat'1 Ctr. for Post-Traumatic Stress Disorder Clinical Newsletter, Fall 1990, at 3 ("Many questions used in clinical tests and interviews . . . are inappropriate in content for assessing ethnocultural minorities and thus do not accurately index problems that may be present."); see also Keane, Kaloupek \& Weathers, supra note 67, at 183 (rejecting a single-instrument approach to diagnosing and assessing PTSD across different cultures).

106. See Fortuna, Porche \& Alegria, supra note 91, at 430.

107. Keane, Kaloupek \& Weathers, supra note 67 at 188.

108. See Marsella, Chemtob \& Hamada, supra note 105, at 3. The National Center for PTSD was created in 1989 and placed within the Department of Veterans Affairs. See History of the National Center for PTSD, U.S. DEP'T OF VETERANS AFF., available 
"individuals from non-Western cultural traditions often fail to present classical symptoms of [anxiety and depressive disorders]." 109 They concluded from this data that "it is quite possible that ethnocultural minority veterans suffering from PTSD and related disorders may be wrongly diagnosed and inappropriately treated." 110 The data supporting these conclusions has persisted for decades. ${ }^{111}$

One of the diagnostic criteria for PTSD is social impairment. "Social impairment" can mean different things to people from different cultural backgrounds and experiences. ${ }^{112}$ The way a veteran expresses his experiences within his social structure may be interpreted as asymptomatic of social impairment. For example, a veteran asked about his relationships with family and friends may respond by describing one close relationship with his brother and his interactions with co-workers each day. Translated into appropriate cultural context, that veteran's experiences may reveal measurable social impairment. A clinician may view the veteran's ability to maintain one or two close friends as evidence of social health, but the same description may be important evidence of social impairment when the clinician considers that the veteran comes from a culture in which substantial community connection and rich social interaction is the norm. ${ }^{113}$ The more socially impaired a veteran is at the time of diagnosis, the higher that veteran's disability rating may be.

Even though research has revealed the clear impact of culture on accurate mental health diagnoses, decisions of the U.S. Court of Appeals for Veterans Claims and the Board of Veterans'

http://www.ptsd.va.gov/about/mission/history_of_the_national_center_for_ptsd.asp (last visited June 14, 2013).

109. See Marsella, Chemtob \& Hamada, supra note 105, at 3.

110. See id.; see also Fortuna, Porche \& Alegria, supra note 91, at 443 ("[There is data showing that culture and race-specific stressors impact the development of PTSD and its chronicity, as well as its symptomatic presentation.”).

111. See, e.g., Fortuna, Porche, Alegria, supra note 91, at 443-44 (noting data showing a clinicians' failure to account for "race-related stressors" may result in the clinician disregarding up to " $20 \%$ of PTSD symptoms").

112. See Spero M. Manson, Ethnographic Methods, Cultural Context, and Mental Illness: Bridging Different Ways of Knowing and Experience, 25(2) ETHOS 249, 251-52 (1997).

113. See Manson, Ethnographic Methods, supra note 112, at 251-52; see also Keane, Kaloupek \& Weathers, supra note 67, at 188. 
Appeals show little discussion or analysis of culture and mental health in the disability claims context. This may be at least in part because self-represented veterans and veterans' advocates alike do not often highlight cultural factors in veterans' psychological disability claims and appeals.

A review of Board of Veterans' Appeals decisions shows one decision that illustrates the power of culture in adjudicating a veteran's psychological disability claim. In 1995, the Board of Veterans' Appeals reopened a finally denied claim from a Texas veteran for a "psychiatric disability." from the military, the veteran had filed a claim for psychiatric disability connected to his service in the Army from 1953 to 1956. During his enlistment, the veteran had been seen at the service medical facilities for "nervousness," vision troubles, and general inability to eat or sleep. He was referred to a psychiatric examiner against his will after he reported, presumably at a service clinic, that he was under an "evil spell" from his wife that had made him impotent and that he was seeing a palmist about the issue. The medical corps psychiatric examiner diagnosed the veteran with a personality disorder (schizoid personality) and described him as a "primitive, superstitious, schizoid, unstable individual" who was "useless to the service" and beyond rehabilitation; the diagnosis did not evaluate the typical criteria for a personality disorder. ${ }^{115}$ The veteran was separated from the service based on this diagnosis, and he then tried to obtain compensation for this psychiatric disability. The VA ultimately denied the veteran's claim because of the personality disorder diagnosis; personality disorders are considered "congenital" or "developmental" and are

114. BVA Docket No. 92-05 460 (1995), available at BD. OF VETERANS' APPEALS, http://www.index.va.gov/search/va/bva.html (search by case number 9503179). According to Rule 1303 of the Board of Veterans' Appeals Rules of Practice, Board decisions are not binding except in the specific case decided. 38 C.F.R. $\S 20.1303$ (2011) (noting that prior Board decisions "may be considered in a case to the extent that they reasonably relate to the case").

115. The Board of Veterans' Appeals decision recounts the independent medical expert's letter many years later that discredited the original diagnosis of personality disorder, noting that "[d]espite the diagnosis, there is no documentation in this examination of the gradual manifestation of withdrawal from social relationships, indifference to the praise or criticism of others, and flattened emotional responsiveness which have characterized this personality disorder for the almost 40 years since this diagnosis was recorded on the appellant." 
not compensable disabilities in the VA system. ${ }^{116}$ Over 40 years later, the veteran petitioned to have his denied claim reopened on the basis of new and material evidence, specifically his many medical encounters for "nervousness" since he was separated from the service and denied disability compensation. ${ }^{117}$ In deciding whether to reopen, the Board of Veterans' Appeals requested an independent medical examination. This was when the veteran's cultural background finally took center stage.

The independent medical expert, reviewing the veteran's diagnoses and medical records from service, explained that the DSM-IV, unavailable in the 1950's when the veteran was in service but available now to aid in reviewing the veteran's medical records, contained an "Outline for Cultural Formulation and Glossary of Culture-Bound Syndromes." The expert noted that one particular culture-bound syndrome, "rootwork," included an interpretation of illness as a "hex" or "witchcraft" or "evil influence" from another person; this fit with the veteran's complaints that led to a diagnosis of personality disorder. Most importantly, the expert noted that culture-bound syndromes like rootwork can "overlap with conventionally understood psychiatric disorders" but actually exist in people viewed as mentally healthy in their culture. The service medical examiner had misinterpreted the veteran's description of his symptoms and use of alternative treatments as "psychosis" related to a "schizoid" personality disorder, but had ignored the veteran's actual "chronic and severe anxiety symptoms" that started during service. The expert stated: "The sequence of a commanding officer unable to understand the appellant's feeling that he was under a spell [and] the officer's revulsion and disapproval at the practice of consulting a non'professional' practitioner ... was probably not unusual at the time."

Ultimately, the expert suggested that the diagnosis of personality disorder, which barred the veteran from receiving

116. See Veterans Benefits Manual, supra note 1, at 158-59 (citing 38 C.F.R. § 3.303(c), 4.9, 4.127 (2011)).

117. A claimant may reopen a previously-denied if the claimant can present "new and material evidence." 38 C.F.R. § 3.156(a) (2011) ("New evidence means existing evidence not previously submitted to agency decisionmakers. Material evidence means existing evidence that, by itself or when considered with previous evidence of record, relates to an unestablished fact necessary to substantiate the claim."). 
disability compensation for a psychiatric disorder, was not justified by the record and "may have been due to a cultural misunderstanding." Instead, the expert opined that the veteran suffered from generalized anxiety disorder that manifested during service and persisted for 40 years. The Board of Veterans' Appeals accepted the expert's opinion as "highly probative" due to his detailed reconciliation and explanation of the personality disorder diagnosis; it reopened the veteran's claim and granted service connection for generalized anxiety disorder.

This is not the only Board of Veterans' Appeals decision in which culture was raised. Board decisions mentioning culture show cases in which culture was simply acknowledged, with no apparent impact on the veteran's diagnosis; ${ }^{118}$ cases in which culture appears to have delayed or confused accurate diagnosis; ${ }^{119}$ cases in which the veteran's culture was explored in psychiatric assessment and considered by the Board increasing a veteran's disability rating; ${ }^{120}$ and cases in which culture became a factor

118. See, e.g., BVA Docket No. 07-00 573 (2012), available at BD. OF VETERANS' APPEALS, http://www.index.va.gov/search/va/bva.html (search by case number 1202272) (veteran was diagnosed with explosive personality disorder, and examiner noted the veteran "had a long history of physical assaultiveness and that he had a need for physical violence, which was deeply ingrained in his Chicano-cultural value of machismo).

119. See, e.g., BVA Docket No. 10-16 510 (2011), available at BD. OF VETERANS' APPEALS, http://www.index.va.gov/search/va/bva.html (search by case number 1139589). In this case out of Texas, the veteran, who was noted as being "culturally diverse," was seen by mental health professionals several times in service due to "odd behavior and poor performance." During service, the psychiatric examiners "were unable to determine an appropriate diagnosis" and speculated that the veteran "could just be a very odd individual, but have no acquired psychiatric disability." A psychiatrist who assessed the veteran while she was in service "speculated that her presentation could be due to cultural diversity and/or childhood abuse." After she left the service, the veteran was diagnosed with schizophrenia.

120. See BVA Docket No. 05-34 352 (2009), available at BD. OF VETERANS' APPEALS, http://www.index.va.gov/search/va/bva.html (search by case number 0921235). This case out of Montana involved an American Indian veteran diagnosed with PTSD by a psychologist at his Tribe's Social Services office. The psychologist noted in his report that he had acknowledged the veteran was suffering from significant internal conflict, even though the veteran was unable to speak freely about that conflict. "[I]t is not a cultural practice for the Veteran to talk openly about feelings and internal conflict, but this was not [to] be interpreted as a lack of internal conflict." Another private counselor further explored the veteran's American Indian background and role as a part-time tribal veterans representative. She noted that, 
supporting a lower disability rating because it explained symptoms that otherwise would have been evidence of a more significant psychological disability as normal within the veteran's culture. ${ }^{121}$ The Board has also remanded cases for new psychiatric examinations with specific instructions to the examiner to consider the veteran's cultural background. ${ }^{122}$ At a minimum, these

although the veteran was reluctant to speak of his traumatic experiences, he opened up about those experiences as a tribal veterans representative when he could "speak of them in his native language with fellow veterans." See also BVA Docket No. 0601766 (2007), available at BD. OF VETERANS' APPEALS, http://www.index.va.gov/search/va/bva.html (search by case number 0727172) (accepting the veteran's evidence from his son-in-law's testimony and private treating physician's statement that the "veteran's cultural background as a Native American interfered with his ability to talk about his PTSD . . . [and] [t] herefore, he was incorrectly rated a lower evaluation").

121. See, e.g., BVA Docket No. 07-10 359 (2010), available at BD. OF VETERANS' APPEALS, http://www.index.va.gov/search/va/bva.html (search by case number 1042930). In this case out of the VA Regional Office in San Juan, the Commonwealth of Puerto Rico, the veteran had long experienced hallucinations "of a religious nature" and heard voices calling him to be a prophet. The veteran's treating psychiatrist, who also lived in that area, explained that "followers of the Pentecostal church in San Juan experience religious hallucinations as part of their spiritual culture," and the symptoms should not be viewed as evidence of psychosis. The Board relied on this opinion to keep the veteran's disability rating for serviceconnected depressive disorder at 50 percent. It reasoned that " $[\mathrm{t}]$ he general rating formula for mental disorders refers to 'persistent delusions or hallucinations' under the criteria for a 100 percent disability rating . . . [but] given the . . . examiner's opinion that the hallucinations are manifestations of his cultural/religious beliefs rather than his mental disorder, the Board finds that the evidence most closely approximates a 50 percent rating." See also BVA Docket No. 06-19 821 (2008), available at BD. OF VETERANS' APPEALS, http://www.index.va.gov/search/va/

bva.html (search by case number 0811920) (denying an increased disability rating for schizophrenia after dismissing the veteran's "persistent hallucinations in the form of seeing, feeling, and hearing dead people" as a normal part of the veteran's Puerto Rican culture, noting the veteran "claims to be a spiritualist, and communication with the dead appears to be a part of his belief system").

122. See, e.g., BVA Docket No. 06-06 094 (2009), available at BD. OF VETERANS' APPEALS, http://www.index.va.gov/search/va/bva.html (search by case number 0928121). In this case out of Seattle, Washington, the veteran alleged in the Board proceedings that the VHA psychiatric examiner had treated him with "cultural insensitivity with civil rights overtones" and "failed to take into account the Veteran's American Indian heritage and culture, and the effect of that heritage and culture on the Veteran's presenting posttraumatic stress disorder symptomatology." Although the Board did not find the record support the veteran's claim of cultural insensitivity in the examination, it remanded for a new psychiatric examination. The 
decisions show that the Board will consider culture as a factor in a veteran's psychological disability claim, particularly if an expert opinion evaluates how culture impacts the diagnosis of or severity of the veteran's psychological disability.

In all the Board's decisions mentioning the veteran's culture, the 1995 Texas case has the most thoroughly-reasoned consideration of cultural factors in a veteran's psychological disability claim. It demonstrates both the profound consequences of misdiagnosis due to cultural misunderstanding, and the power of a thorough exploration of cultural factors in diagnosing a veteran's psychological disability. The Board of Veterans' Appeals requested the independent medical examination in that case, but an advocate could pursue the same in a case that involved similarlysignificant cultural factors. Either way, the consideration of cultural as a factor could dramatically alter the outcome of a veteran's disability claim.

\section{AdVOCATING FOR CULTURALLY-INFORMED ASSESSMENT, TREATMENT, AND COMPENSATION IN THE VA SYSTEM}

As advocates for veterans with psychological disability claims, we can be truly effective only if we are aware of how important a veteran's culture is to psychological assessment and treatment. Culturally-informed representation is critical at every stage of the claim and appeal process.

\section{A. Improve Personal Cultural Awareness ${ }^{123}$}

Improving our own awareness of cultural and ethnic factors in the mental health context will improve advocacy at all stages of

Board directed the new examiner to specifically "include an assessment of the impact of the Veteran's American Indian heritage and culture on his presenting psychiatric symptomatology."

123. Some critics of cultural competency approaches to lawyering argue that a focus on cultural competency "raises a real risk of further perpetuating stereotypes." See Andrew King-Ries, Just What the Doctor Ordered: The Need for Cross-Cultural Education in Law Schools, 5:1 TENN. J. L. POL'Y 27, 51 (2009) (citing Janelle S. Taylor, Confronting "Culture" in Medicine's "Culture of No Culture", 78 ACAD. MED. 555, 555 (2003)). This article attempts to remain sensitive to this risk by advocating for improved cultural awareness in advocacy for clients of all perspectives and being mindful that "culture is something that belongs to and shapes everyone." See King-Ries, supra, at 51-52. 
representation in the VA system. Just as mental health clinicians must be aware of their own cultural and ethnic identity to accurately assess veterans, ${ }^{124}$ lawyers representing diverse veterans should also educate themselves about how their own culture and ethnicity has shaped them so they are aware of their potential ethnocentric points of view or cultural biases. Clinicians studying culture and mental health recommend considering the following factors:

(1) the cultural influences of the dominant society;

(2) the cultural identity and background of the practitioner; (3) the institutional culture of the hospital, clinic, or other setting where diagnosis and treatment are delivered; and (4) the professional cultures of biomedicine and psychiatry. ${ }^{125}$

We must embark on a similar self-evaluation at the early stages of representation, considering our own cultural identities and backgrounds, what influences our understanding of our clients' cultural and ethnic groups, and the institutional and professional culture in which our clients will be assessed, including both the legal profession and the VA.

\section{B. Conduct a Culturally-Sensitive Initial Client Interview}

Veterans' advocates should appreciate the importance of culture to the psychological context in the earliest stages of representation. The DSM-IV Cultural Formulation, reprinted in Appendix A, though designed for use by mental health professionals, offers a good starting point for constructing a culturally-sensitive initial client interview. Advocates aware of the outline could use it to construct a series of interview questions designed to elicit information about the veteran's cultural identity or cultural reference groups, "stresses in the local social environment and the role of religion and kin networks in providing emotional, instrumental, and information support," and any

124. See Mezzich, Caracci, Fabrega, Jr. \& Kirmayer, supra note 54, at 391 ("Culture may be significant not only for the content, values, meanings, and practices of patients and families, but also for understanding the clinician's point of view.").

125. See Mezzich, Caracci, Fabrega, Jr. \& Kirmayer, supra note 54, at 39192. 
difficulties the veteran has had or may have in communicating with clinicians (e.g., language difficulties). ${ }^{126}$

Advocates should also explore the veteran's history of mental health treatment both inside and outside of the VHA system. The veteran's cultural background may have affected whether and how often the veteran accessed mental health and other medical services, regardless of symptomatology. ${ }^{127}$ Exploring the veteran's personal history of treatment or lack of treatment and inquiring into the reasons for not seeking treatment, not seeking treatment as often as needed, or seeking treatment from non-traditional practitioners can lead to crucial information demonstrating the veteran's illness was ongoing since service despite the absence of significant care. ${ }^{128}$ For example, in a 2008 Board of Veterans' Appeals decision out of San Diego, California, the Board noted the veteran's treating physician's opinion that "the veteran did not complain of symptoms in psychological terms or seek treatment for them at least partially out of a sense of shame and guilt commonly seen and perceived in his ethnic culture." Based on the physician's opinion and the veteran's supporting lay witness statements describing his symptoms since service, the Board held the veteran had demonstrated "a continuity of

126. See DSM-IV, supra note 44, at Appendix I (Outline for Cultural Formulation) (reprinted in Appendix A).

127. See Dep't Health \& Human Servs., supra note 59, at 25 ("Cultural misunderstandings between patient and clinician, clinician bias, and the fragmentation of mental health services deter minorities from accessing and utilizing care and prevent them from receiving appropriate care.”).

128. This may be an important consideration in a psychological disability case, particularly if the diagnosis came after the veteran was discharged from service. See 38 C.F.R. $\S \S 3.303(b)$, (d) (2011); see also VETERANS BENEFITS MANUAL, supra note 1, at 119 ("Under the continuity provisions of $\S 3.303$ (b), service connection may be granted where 'a disease manifests itself during service (or during the presumptive period) but is not identified until later, there is a showing of continuity of symptomatology after discharge, and medical evidence relates the symptomatology to the veteran's present condition."' (quoting Rose v. West, 11 VET. APP. 169, 171 (1998)); Veterans BenEFITS MANUAL, supra, at 160 ("As with any other service-connected disability claim, in addition to a diagnosis of current disability, the veteran will need evidence that the mental disorder was incurred in or aggravated by military service and evidence that links the mental disorder to service as described in Sections 3.3 and 3.4 [of this Manual].”). 
symptomatology from active service to present," and granted service connection for an acquired psychiatric disorder. ${ }^{129}$

In addition, an advocate should inquire into the veteran's familial structure, looking broader than just biological family to the extended "family" that may include community elders or leaders and friends close to the family but not related by blood. ${ }^{130}$ This could expand the list of witnesses who may be able to provide supportive observations of the veteran's day-to-day symptoms, information about the veteran's culture, and at times even comparative observations between the veteran's culture and neighboring or surrounding cultures to illustrate potential cultural variables relevant to diagnosis. ${ }^{131}$

For example, an advocate may first construct the family tree, and then ask the client for a list of any other individuals the client goes to for advice or considers an authority to consult in making decisions. ${ }^{132}$ All of these individuals are potential witnesses who could inform and contribute to an advocate's initial materials submitted with the claim and thus help the VHA C\&P Examiner accurately assess the veteran and the VBA gatekeeper's

129. BVA Docket No. 06-00 318 (2008), available at BD. OF VETERANS' APPEALS, http://www.index.va.gov/search/va/bva.html (search by case number 0818114). An advocate planning to argue that the veteran did not seek traditional medical or psychiatric treatment since service for cultural reasons will need to sufficiently support this argument with evidence showing the veteran was still suffering from symptoms of the diagnosed mental illness or had sought nontraditional treatment. The Board of Veterans' Appeals has rejected this argument when it has been unsupported by additional evidence. See, e.g., BVA Docket No. 0737 965A (2009), available at BD. OF VETERANS' APPEALs, http://www.index.va.gov/search/va/bva.html (search by case number 0911261) (rejecting advocate's apparently unsubstantiated argument that the veteran's "cultural practices" prevented him from seeking medical treatment for his breathing symptoms and required him to use natural remedies instead); BVA Docket No. 0416203 (2008), available at BD. OF VETERANS' APPEALs, http://www.index.va.gov/search/va/bva.html (search by case number 0827374) (rejecting a veteran's claim that she had not sought treatment for depression because of her "Midwestern culture" when her record had no supporting lay or medical evidence to show she had been suffering from symptoms of depression since service).

130. See Christensen, supra note 60, at 4-5.

131. See id. at 5-6.

132. See id. (discussing familism and extended family network as critical cultural variables to consider in mental health diagnosis). 
accurately rate the veteran's disability. If the veteran's claim has already been denied, the advocate may find in these witnesses someone who can offer new and material evidence about the influence of culture on the veteran's disability that may be enough to meet the standard of reopening the claim.

\section{Gather Culturally-Relevant Supportive Evidence}

As the advocate gathers supportive evidence to support a claim, the advocate should also consider how evidence about the veteran's cultural and ethnic identity may help inform future psychological assessment. In order to gather reliable evidence about the veteran's cultural identity and background for this purpose, an advocate may consider involving an individual intimately familiar with the veteran's cultural background who could inform culturally-appropriate development of the veteran's claim. This type of consultant may be referred to as a "culture broker." 133 Culture brokers may be professional clinicians or leaders in the veterans' communities who can speak to both "(1) the health values, beliefs, and practices within [the culture broker's and veteran's] cultural group or community and (2) the health care system that they have learned to navigate effectively for themselves and their families."134

Assessment from a civilian psychiatrist with experience or a specialty in multicultural mental health assessments may also provide crucial evidence in a case involving strong cultural factors. Richard G. Dudley, Jr., and Pamela Blume Leonard have constructed a checklist of factors to consider when selecting a mental health expert with ethno-cultural competence in the context of capital trials. This checklist could inform veterans' advocates selecting a private mental health expert to assess a veteran with psychological disability claim that has potentially-significant cultural factors:

133. The National Center for Cultural Competence at Georgetown University Center for Child and Human Development describes a culture broker as one who serves as an intermediary by "bridging the cultural gap by communicating differences and similarities between cultures." See Nat'l Ctr for Cultural Competence, Bridging the Cultural Divide in Health Care Settings: The Essential Role of Cultural Broker Programs 3 (2004).

134. See Nat'l Ctr for Cultural Competence, supra note 133, at 3. 
Does [the expert] understand the ethno-cultural context of the information gathered?

Can the expert effectively engage, communicate with, and form a working relationship with a person of the defendant's ethno-cultural group ... ?

Does [the expert] have the capacity to integrate what we know about the impact of ethnicity and culture on human behavior into what we know about the behavioral sciences?

Does the expert employ ethno-culturally appropriate theories and empirical data when rendering opinions? ${ }^{135}$

With culture becoming a central focus in many medical training facilities, including medical schools, finding private physicians with these qualifications should only get easier in the coming decade. ${ }^{136}$ In addition to providing a private psychiatrist with the veteran's entire VA claims file (known as a C-file), including the veteran's treatment records from service, ${ }^{137}$ the advocate could ask the private psychiatrist to specifically apply the Cultural Formulation Outline and address potential cultural factors the

135. See Dudley \& Leonard, supra note 61, at 978-79.

136. See Lynn M. Morgan, "Life Begins When They Steal Your Bicycle": Cross-Cultural Practices of Personhood at the Beginnings and Ends of Life, 34 J.L. MED. \& ETHICS 8, 8 (2006) ("[M] the rage in medical schools and hospitals across the country, as manifested in the explosion of programs designed to teach what is called 'cultural competence."').

137. The VETERANS BENEFITS MANUAL includes exhaustive advice on presenting a private mental health assessment that will be acceptable to the VBA rating specialist. See Veterans Benefits Manual, supra note 1, at Section 17.6.5.2. It warns that the VA often discredits private medical and mental health opinions when the physician did not have access to or did not review the veteran's entire claims file. VETERANS BENEFITS MANUAL, supra, at 1449 ("When balancing positive and negative medical opinions, the VA tends to discredit the positive opinion if the physician providing the positive opinion did not review the veteran's claims file or at least his or her service treatment records (STRs).”). 
advocate identified in the initial client interview or that have been raised with past treating psychiatrists. ${ }^{138}$

\section{Advocate for Culturally-Informed Diagnosis within the VA}

VA regulations recognize that an "accurate and fully descriptive medical examination []" ${ }^{, 139}$ is a necessary pre-condition to accurate application of the VA disability rating schedule. Thus, a veteran's lawyer should advocate for a culturally-competent C\&P Examination as early as possible in the claim process. ${ }^{140}$

After a veteran has been assessed by a C\&P Examiner, the veteran's advocate may review that clinician's report through the lens of cultural factors the advocate knows, through research and perhaps the assistance of a culture broker, to be crucial to accurate calibration of the severity of the veteran's disability. At least, an advocate should immediately note whether the Examiner explored potential cultural factors with the veteran using the Cultural Formulation Outline. If the report includes no apparent exploration of potential cultural factors, and the diagnosis (or lack of diagnosis) seems erroneous as a result, to the veteran's disadvantage, the advocate may call attention to the error before the VBA rating specialist. ${ }^{141}$ Submitting evidence and supplemental information about potential cultural factors in the

138. An advocate using the Veterans BenEFITS MANUAL will find a thorough description of how to prepare for a private medical assessment, including points to include in a cover letter sent to the private medical expert. See VETERANS BENEFITS MANUAL, supra note 1 , at Section 17.6.5. In addition, the MANUAL includes a sample cover letter to a medical expert requesting a medical opinion. VETERANS BenEFITS MANUAL, supra, at Appendix 17-C. This article proposes that veterans' advocates should consider including in such a letter information on potential cultural factors in the veteran's mental illness and a specific request that the medical expert apply the Cultural Formulation Outline in the DSM-IV.

139. 38 C.F.R. $\S 4.1$ (2011).

140. This will, again, help prevent unnecessary appeals and remands, which result in veterans waiting many years for final decisions on their claims. See VETERANS BENEFITS MANUAL, supra note 1 (discussing the average number of days it takes for the VA and BVA to decide claims at various stages).

141. See Veterans BenEfits MANUAL, supra note 1, at 158 ("Advocacy Tip . . . If the veteran's symptoms differ significantly from the DSM-IV criteria, and the advocate believes that the veteran is disadvantaged by the diagnosis, the advocate should consider requesting the VA to schedule another mental examination, and, if practical, suggest that the veteran obtain an independent medical diagnosis from a private physician."). 
veteran's situation at this time could cause the VBA rating specialist to appropriately return the clinician's report as "inadequate for evaluation purposes." 142

\section{E. Advocate for Culturally-Appropriate Treatment in the VA}

Advocates may also consider whether cultural factors should influence the veteran's ongoing treatment. One concrete example of how crucial culturally-appropriate treatment may be to a veteran's ongoing quality of life comes from American Indian culture groups. Research in American Indian tribes has shown that a person's ties to traditional ways or cultural involvement, also known as enculturation, could predict the person's resilience in difficult life circumstances or psychological distress. ${ }^{143}$ This includes various connections to tribal culture-like traditional health practices. ${ }^{144}$ Traditional health practices are found to "buffer" stress and improve a person's coping skills. ${ }^{145}$ If an American Indian veteran follows traditional ways, a treatment plan should encourage and incorporate traditional health practices to improve the veteran's resilience in living with a psychological disability; because alienation from traditional ways has been linked to mental health risks, some researchers suggest careful assessment of the extent to which an American Indian patient engages in and identifies with the traditional culture of his or her tribe in formulating an appropriate treatment plan. ${ }^{146}$ This example illustrates how advocating for a treatment plan that integrates

142. 38 C.F.R. $\S 4.2$ (2011) ("If a diagnosis is not supported by the findings on the examination report or if the report does not contain sufficient detail, it is incumbent upon the rating board to return the report as inadequate for evaluation purposes.").

143. Carrie Winderowd, Diane Montgomery, Glenna Stumblingbear, Desi Harless \& Kaycie Hicks, Development of the American Indian Enculturation Scale to Assist Counseling Practice, 15(2) American Indian and Alaskan Native Mental Health 1, 1-2 (2008).

144. See id. at 2 ("Prominent among the resiliency factors were traditional cultural and spiritual practices; ethnic pride/enculturation; and communal mastery leading to higher life satisfaction, more adversarial growth, and lower levels of psychological distress.").

145. See id. at 2 (also listing identity attitudes, enculturation, and spiritual coping as "cultural buffers" to stress).

146. See id. at 4 (recognizing that "[e]ach tribe has its own unique characteristics and ways of life, which must be respected in any generalized measurement result"). 
traditional health practices for a veteran who shows a high level of enculturation rises to the level of an "ethical priority.",

\section{CONCLUSION AND FUTURE CONSIDERATIONS}

In the VA system, the psychiatrist (examining the veteran for an administrative purpose) and the rating specialist (rating the veteran's disability based on the psychiatrist's report) are the gatekeepers who hold the keys to the veteran's compensation for a service-connected psychological disability. A veteran must be able to effectively communicate with these gatekeepers; this will lead the veteran into the right "line" to receive the "envelope" that most appropriately compensates the lost ability to earn an income. Communication between the veteran and the medical examiner is a truly pivotal part of the veteran's claim, and advocates aware of how culture can impact this communication will be more effective in getting their veteran clients into the right line. Right now, the DSM-IV Cultural Formulation Outline is a helpful tool for advocates to become more familiar with cultural factors in diagnosis. In the future, advocates should closely watch for a VA transition to the DSM-5 and become familiar with its cultural formulation interview guide. ${ }^{148}$ An advocate fully informed of potential cultural factors in a veteran's case will make the veteran's cultural identity a part of the record early in the claim process; in doing so, the advocate will help the veteran obtain more accurate and appropriate diagnosis, rating, and treatment.

147. See id. at 3 .

148. See American Psychiatric Publishing, DSM-5 Fact Sheets, Cultural Concepts in DSM-5, http://www.psychiatry.org/DSM5 (last visited June 14, 2013) ("Finally, the cultural formulation interview guide will help clinicians to assess cultural factors influencing patients' perspectives of their symptoms and treatment options. It includes questions about patients' background in terms of their culture, race, ethnicity, religion, or geographical origin.”). 


\section{APPENDIX A}

\section{DSM-IV-TR Diagnostic and Statistical Manual of Mental Disorders}

\section{Appendix I}

\section{Outline for Cultural Formulation ${ }^{149}$}

The DSM-IV-TR asks the clinician to summarize, in narrative, his or her findings in each of the categories below.

Cultural identity of the individual. Note the individual's ethnic or cultural reference groups. For immigrants and ethnic minorities, note separately the degree of involvement with both the culture of origin and the host culture (where applicable). Also note language abilities, use, and preference (including multilingualism).

Cultural explanations of the individual's illness. The following may be identified: the predominant idioms of distress through which symptoms or the need for social support are communicated (e.g., "nerves," possessing spirits, somatic complaints, inexplicable misfortune), the meaning and perceived severity of the individual's symptoms in relation to norms of the cultural reference group, any local illness category used by the individual's family and community to identify the condition (see "Glossary of Culture-Bound Syndromes" below), the perceived causes or explanatory models that the individual and the reference group use to explain the illness, and current preferences for and past experiences with professional and popular sources of care.

Cultural factors related to psychosocial environment and levels of functioning. Note culturally relevant interpretations of social stressors, available social supports, and levels of functioning and disability. This would include stresses in the local social environment and the role of religion and kin networks in providing emotional, instrumental, and informational support.

Cultural elements of the relationship between the individual and the clinician. Indicate differences in culture and social status between the individual and the clinician and problems that these

149. Reprinted from Psychiatry Online DSM Library, available at http://psychiatryonline.org/content.aspx?bookid=22\&sectionid=1886266 (last checked August 2012). 
differences may cause in diagnosis and treatment (e.g., difficulty in communicating in the individual's first language, in eliciting symptoms or understanding their cultural significance, in negotiating an appropriate relationship or level of intimacy, in determining whether a behavior is normative or pathological).

Overall cultural assessment for diagnosis and care. The formulation concludes with a discussion of how cultural considerations specifically influence comprehensive diagnosis and care. 